\title{
Both patient and stone factors determine "best" treatment for urolithiasis
}

\author{
John Dushinski, MD \\ Southern Alberta Institute of Urology, Calgary, AB, Canada
}

Cite as: Dushinski J. Both patient and stone factors determine "best" treatment for urolithiasis. Can Urol Assoc J 2021;15(12):394. http://dx.doi.org/10.5489/cuaj.7681

See related guideline on page 383

$\mathrm{T}$ he Canadian Urological Association last published guidelines on the management of ureteral calculi in 2015. The intervening years have seen a continued increase in the prevalence and cost of stone management in the Western world. There has also been a gradual move to more ureteroscopy and less shockwave lithotripsy, as ureteroscopic instruments have improved and urologists have become more comfortable using them.

Developing guidelines for the management of stone disease is challenging due to the massive amount of literature on the subject and the lack of standards for many of the factors used to evaluate patients. Nevertheless, several stone factors, such as size, composition, and location, as well as patient factors, such as degree of pain and nausea and history of previous stone passage, can help guide treatment.

As the authors of this 2021 guideline illustrate, conservative management has been shown to be effective with small $(<5 \mathrm{~mm})$ stones; ureteroscopy and shockwave lithotripsy are both reasonable options for larger stones and stones that do not pass with conservative management. ${ }^{1}$ Stone factors and patient factors can be used to determine which is the "best" treatment in a given situation, although the decision may ultimately depend on local resources.

The authors are to be congratulated for their exhaustive review of the literature and their reasonably succinct final product.

Urologists must always evaluate both patient and stone factors and use a shared decision-making process with the patient prior to determining a management strategy for urolithiasis.

Competing interests: The author does not report any competing personal or financial interests related to this work.

\section{Reference}

1. Lee JY, Andonian S, Bhojani N, et al. Canadian Urological Association guideline: Management of ureteral calculi. Can Urol Assoc J 2021;15:383-93. htrp://dx.doi.org/10.5489/cuai.7652

Correspondence: Dr. John Dushinski, Southern Alberta Institute of Urology, Calgary, AB, Canada; jdushinski@shaw.ca 